\title{
The Exploration of the Mixed-Mode Teaching Based on the "MOOC+SPOC"
}

\author{
Youliang Huang ${ }^{1 *}$, Fengying Guo ${ }^{1 *}$, Nan $\mathrm{Jiao}^{2}$, Na Yuan ${ }^{2}$, Juan Wang ${ }^{2}$, Xing Zhai ${ }^{1}$, Renquan Liu ${ }^{1}$ \\ ${ }^{1}$ Information Center, Beijing University of Chinese Medicine, China \\ ${ }^{2}$ Teaching Affairs Department, Beijing University of Chinese Medicine, China
}

\begin{abstract}
MOOC has attracted many learners from all over the world with the advantages of open resources, low registration threshold and independent learning. As a new online education model, MOOC is a challenge and opportunity for the traditional higher education. SPOC is the product of the development of MOOC. It combines MOOC with traditional campus teaching effectively, and it is a blended teaching model based on MOOC. It has the characteristics of Small-scale Specific groups and online open. SPOC promote the brand effect of the University and improvement the teaching quality of school cost. This paper briefly introduces the development of MOOC and SPOC, expounds the concepts and characteristics of MOOC and SPOC, and discusses the implementation and application of MOOC+SPOC based blended teaching model in College teaching.
\end{abstract}

Keywords-MOOC; SPOC; Mixed model teaching; Higher Education

\section{INTRODUCTION}

Under the background of informatization and globalization, information technology is constantly impacting teacher education, and all countries around the world have studied and explored how to reform teacher education under the background of the new era. The essence of education is the formation of the transmission of knowledge and wisdom. With the development of Internet technology, cloud computing, sensor technology, networking and massive information processing and new equipment, have a transformative effect on the connotation of information technology, the traditional education of the process of learning and teaching and education output [1]. Information technology has greatly changed the teaching methods of teachers in education and teaching, and the traditional classroom teaching mode has been greatly impacted. More and more literatures show that the use of digital educational technology is rapidly expanding in the field of education and teaching, and it has become a high priority for institutions of higher learning and many academic institutions. Technological advances across the globe have led to innovations in blended learning (combining classroom and online education). And then spawned mobile learning, blended learning and MOOC, the emergence of the flipped classroom, micro courses, mixed teaching and other new education theory, and constantly led many front-line teachers to carry out classroom teaching reform. In the era of global network information, as a new era of people, lifestyle and living habits have undergone tremendous changes, education has also been a new reform [2]. Network teaching has been favored by the majority of people, such as: Micro class, MOOC, flipped classroom and other educational models have also been the attention of various educational circles.

\section{MOOC AND SPOC}

MOOC (Massive Open Online Course), that is, large-scale open online courses. In 2012, some American universities took the lead in offering free courses on the internet. At present, the rapid development of Coursera, Udacity, edX three, MOOC three, has become a major platform provider, creating a new and fair education mode, to provide a free learning platform for more people [3]. The idea of MOOC gradually attracts more and more universities' attention, and then begins to construct MOOC courses. At the same time, domestic universities pay close attention to the development of MOOC, since the three universities of Tsinghua University, University of Hong Kong and Hong Kong University Science \&amp; Technology in May 2013 to join edX, domestic universities have joined the reformation of the education mode of this new wave of MOOC then established the school online, "good university" and other domestic MOOC platform. Provide free receive quality education and innovation education share bonus opportunity MOOC for more people, with its "short video" as the basic teaching unit of the "fragmentation" learning mode, which is convenient for students to use fragments of time viewing and leisure whenever and wherever possible, more conducive to the knowledge of memory, understanding, digestion and absorption. At the same time, MOOC for learners to create immersive, socializing a teach and learn in the learning environment and instant feedback interactive training platform.

SPOC is a new concept derived from 2013 on the basis of MOOC, MOOC in 2012 after the birth of the rapid Fashionable all over the world. SPOC (Small, Private, Online, Course), that is, a small-scale restricted online course. It was proposed in 2013 by Professor Armando Fawkes of the University of California at Berkeley in the United States. Compared to MOOC's massive and open, SPOC is characterized by small and private. Small refers to the size of students, usually in the tens to hundreds of people; private refers to the course set access conditions. It is a small and sophisticated course type, which is more suitable for the application of school-based curriculum in Colleges and universities. SPOC is the product of the development of MOOC. It combines MOOC with traditional campus teaching effectively, and it is a blended teaching model based on MOOC. SPOC is a new form of 
MOOC localization, in the SPOC case, often using MOOC. SPOC teaching is the use of flipped classroom, online courses to a large extent instead of the traditional curriculum teaching, through the establishment of curriculum learning conditions, design online teaching, learning evaluation and later data analysis [4]. SPOC better than MOOC better play the advantages of online education, SPOC's small and private are for MOOC's massive and open, for example.

As a supplement of classroom teaching media, MOOC has begun to show various disadvantages in the course of its development. For example, some of the "Mu class" content is more for the off campus learners, its knowledge content and rigor is difficult to reach the university curriculum standards and requirements. Such a class course is difficult to match with the teaching objectives, the degree of difficulty and the accumulation of the existing knowledge of the learners. Some foreign top universities will try a more elaborate course types, namely SPOC. SPOC is a kind of "school-based" development based on MOOC learning platform is combined with the depth of MOOC and application of classroom teaching, is the online curriculum resources and teaching a better integration of online and offline combination of new teaching mode. It can enhance teachers' leverage, students' throughput, students' mastery, and students' participation degree [5]. The traditional classroom is the teacher at the core of the teaching mode, the paper mainly adopts the teaching method, from the selection of teaching materials to implement, is completely in a fixed, closed, can control the situation in the teaching activities, resulting in the students only Passively accept the knowledge taught by teachers, teachers teach activities according to the inherent form of teaching, learners learn according to the content and progress of the teaching preparation prepared by the teacher. Flip the classroom, is to subvert the traditional classroom "," one for attention "Individual learning" is a new teaching mode. Many teaching practices at home and abroad show that blended learning can help to maximize the efficiency of teachers, increase students' participation, attract more students, and improve the retention rate of memory [6]. One of the application of blended learning has gained popularity in the past few years, it is flipped classroom.

Figure 1 shows the comparison between SPOC and MOOC compared with MOOC, SPOC has the advantages of: (1) mode of freedom: SPOC teaching content can be a superset of MOOC, teachers can open MOOC, at the same time, a small number of students SPOC asked the latter to choose MOOC at the same time, through other channels (online the online discussion, hybrid teaching or offline (including flipping to achieve SPOC, SPOC+MOOC) of communication mode. (2) full attention: but fewer students, can achieve the learning process the teacher involvement of students, including by teacher or teaching assistant, marking the completion of the full exchange and answering and discussion between students' homework, even face to face makeup" [7]. In contrast, in MOOC, generally speaking students independent learning or basic, even if there is a discussion area, one of the few students active stage, and after the question answers the efficiency is not directly asked the teacher. (3) Attendance: Although the excellent teacher is not to worry about attendance, but cannot be denied, SPOC can explicitly or implicitly form attendance to students (whether online or classroom classroom) pressure, which is beneficial for some relatively inert students. Of course excessive and one-sided pursuit of attendance often leads to students' disgust, while MOOC has much lower restrictions on students [8]. (4) Consistent progress: students have a consistent schedule, in fact, is very favorable. Even in the course of the discussion area, can also form a concentrated focus. SPOC, through periodic or no periodic offline communication, actually forces students to have basically the same schedule when they participate in offline communication. (5) Students: Student's isomorphic differences in the distribution of MOOC was significantly higher than SPOC. The latter can pass the entrance examination, placement and other ways to screening and breakdown of the students. Students from a wide range of areas, with different ethnic groups, religious beliefs, ways of thinking are different, paying attention to observe different places, which is likely to produce some sparks in some emphasize the communication between students in MOOC, even the teacher can give some inspiration. But their difference is too large, it is more difficult to achieve good teaching effect. In any case because the course is most suitable for a part of students (most of the students such as student's differences in the level of normal distribution, teachers generally choose the middle reaches of the key as the object, to take care of care for the best and worst students less). (6) Teach students in accordance with their aptitude: teachers can fully understand the various aspects of the students' information (previous curriculum performance, past performance, personality, advantages and disadvantages, etc.). It is also the case, is it possible to do a real aptitude in the classroom, such as some key points, based on different students, some students volunteered to do some special consideration. (7) Identity verification: on this point, SPOC can guarantee students to listen to lectures, but also can do the line exam, and MOOC is unlikely, which also directly led to the MOOC curriculum certificate gold content is less than SPOC [9].

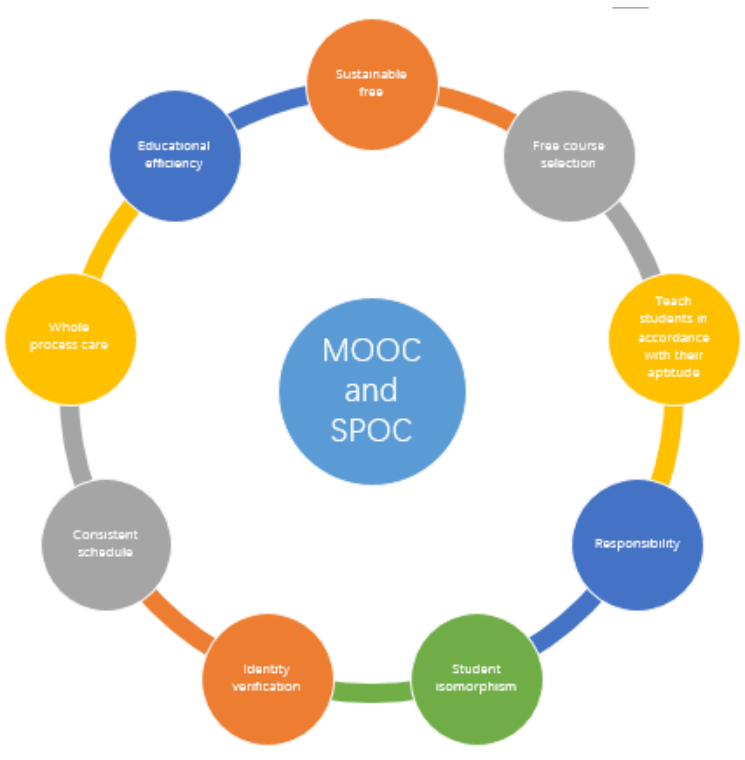

Fig. 1 Comparison of SPOC and MOOC 


\section{APPLICATION AND IMPLEMENTATION OF MOOC+SPOC IN HIGHER EDUCATION}

Due to the lack of pertinence and the simple presentation mode, MOOC cannot participate online in real time, and these limitations are difficult to meet the differentiated learning needs of different levels of knowledge. MOOC, SPOC and micro class all the online teaching is difficult to take into account the different learners starting point and knowledge ability, teaching content of the basic online cannot be stereotyped, hierarchical teaching, cannot be purely theoretical courses It differs from man to man., do not meet the personalized teaching of different students, on practical computer software development courses online teaching cannot meet the needs of the students, but the online teaching as a teaching aid is very necessary in the traditional classroom [10].

The emergence of MOOC was aimed at achieving a fair education, and SPOC was designed to integrate MOOC and school classes. At present, the MOOC+SPOC blended teaching model explored in this paper is mainly composed of three stages: pre class preparation, class teaching and after-school exercises [11]. Pre class preparation stage, the main arrangement of students to watch MOOC related teaching video. Do not require students to understand completely, but must go to see, do a good job before class preparation, the basic content of the course to understand [12]. In the class teaching stage, the teacher compares the existing teaching resources with the MOOC teaching resources, so as to achieve complementary advantages, focus, and practice. After the practice stage, students pass the school SPOC platform for homework, test, discussion, and so on, to test the students' mastery of knowledge [13]. Through the SPOC platform, students can discuss with each other; mutual evaluation results, teachers can view each student's learning progress, online communication with students, targeted personalized counseling the common problems, to focus on in the classroom. Through the practice of MOOC+SPOC teaching model, we found that before the class to watch the MOOC video teaching is very important [14], the classroom for students to quickly understand and accept new knowledge, can speak some teaching cases in teaching this class, students have more opportunities to practice, improve practical ability.

\section{CONCLUSION}

"MOOC+SPOC" is the direction of the future university education reform, and the mixed-model teaching based on MOOC+SPOC is beneficial to individual and specialized teaching in different universities. MOOC has solved the network teaching of the content stipulated in a course, and SPOC has solved the difference network teaching of different schools and different crowds. MOOC+SPOC solves the problem with the traditional classroom teaching resource sharing stereoscopic course together, to realize multi-channel learning, repeated learning, without time limit the freedom of learning model makes the effective fusion line and online teaching, promote teaching reform, improve teaching quality, promote teachers and practice worthy of our university. The traditional higher education how to gain a foothold in the face of opportunities and challenges, making up In short, developing, how to utilize the network teaching, teaching in the new era There are new developments and innovations that are values To be studied.

\section{ACKNOWLEDGMENT}

The authors are very grateful to the referees and anonymous reviewers for their helpful comments and suggestions. This work was supported, in part, by Beijing University of Chinese Medicine (Grant No. XJY16040 and Grant No. XJZX1613), by Medical education branch of Chinese medical association (Grant No. 2016B-JJ023) by Beijing University of Chinese Medicine (Grant No. 2016-JYBQNJSZX005).

\section{REFERENCES}

[1] Kang Y. An Analysis on SPOC: Post-MOOC Era of Online Education[J] Tsinghua Journal of Education, 2014, 46(5):83-85.

[2] Mutawa A M. It is time to MOOC and SPOC in the Gulf Region[J]. Education \& Information Technologies, 2017, 22:1-21.

[3] Coulson K V, Armellini A, Farmer R. MOOC and SPOC: a tale of two courses [J]. 2014.

[4] He B, Cao Y. SPOC: MOOC-based Innovation of Teaching Processes[J] China Educational Technology, 2015.

[5] Bao Q L, Qiao Y T, Zhi-Yuan L I. From MOOC to SPOC: The Revelation for Remote Online Military Vocational Education[J]. Journal of Higher Education Research, 2015.

[6] Ji L, Zhang Y, Li S, et al. Construction of Biochemistry Open Online Curriculum in Local Universities Based on MOOC/SPOC [C]// Conference on Education and Teaching in Colleges and Universities. 2017.

[7] Combéfis S, Bibal A, Van Roy P. Recasting a Traditional Course into a MOOC by Means of a SPOCNo Title[J]. Publié, 2014.

[8] Vicente M T P, Bertomeu I M, Molina J A L, et al. Del MOOC al SPOC Una experiencia para el aprendizaje líquido de la Química básica[C]// Red 2015 - Congreso Nacional De Innovación Educativa Y Docencia En Red. 2015:589-598.

[9] Xie A, Jiang Y, Luo S, et al. Construction of SPOC blended teaching mode of physical chemistry experiment in post-MOOC era[J]. Experimental Technology \& Management, 2016.

[10] Ferreira A. DU MOOC AU SPOC: Classe inversée en langue de spécialité[C]// Questions De Pédagogie Dans L'enseignement Supérieur. 2015:256-261.

[11] Baggaley J. MOOC postscript[J]. Distance Education, 2014, 35(1):126132.

[12] Piccioni M, Estler C, Meyer B. SPOC-supported introduction to programming $[\mathrm{C}] / /$ Conference on Innovation \& Technology in Computer Science Education. ACM, 2014:3-8.

[13] Martínez-Muñoz G, Pulido E. Using a SPOC to flip the classroom[C]// Global Engineering Education Conference. IEEE, 2015:431-436.

[14] Ramírez-Donoso L, Rojas-Riethmuller J S, Pérez-Sanagustín M, et al. MyMOOCSpace: A cloud - based mobile system to support effective collaboration in higher education online courses [J]. Computer Applications in Engineering Education, 2017. 